\title{
PENINGKATAN KEMAMPUAN KEPALA SEKOLAH DALAM MENYUSUN RENCANA PENGEMBANGAN SEKOLAH (RPS) MELALUI PEMBINAAN BERKELANJUTAN DENGAN METODE WOKSHOP TAHUN 2019 \\ IMPROVING SCHOOL HEAD CAPABILITIES IN DEVELOPING SCHOOL DEVELOPMENT PLANS THROUGH SUSTAINABLE DEVELOPMENT WITH THE WOKSHOP METHOD IN 2019
}

\author{
SUGENG \\ Surel: sugeng.rohim@yahoo.co.id \\ Pengawas Dinas Pendidikan Kabupaten Pandeglang
}

\begin{abstract}
Abstrak
Berdasarkan hasil analisis pada masing masing siklus menunjukkan peningkatan Kinerja Kepala Sekolah dalam menyusun Rencana Pengembangan Sekolah (RPS) yakni: peningkatan banyaknya Kepala Sekolah yang mampu menyusun Rencana Pengembangan Sekolah (RPS) dari siklus I ke siklus II. Dengan demikan dapat disimpulkan bahwa melalui kegiatan Workshop dapat meningkatkan Kinerja Kepala Sekolah dalam menyususn Rencana Pengembangan Sekolah (RPS) pada Rayon 2 yang ada di Pandeglang, Dengan workshop kemampuan Kepala Sekolah dapat ditingkatkan, utamanya kemampuan menyusun RPS yang sebelumnya mereka beranggapan bahwa RPS adalah pelengkap administrasi kepala sekolah belaka. Hal ini dibuktikan dengan memperoleh nilai 72,14 pada siklus I dan meningkat menjadi 85,71 pada siklus II .
\end{abstract}

Kata Kunci : Rencana Pengembangan Sekolah, Wokshop,Kepala Sekolah

\begin{abstract}
The determined performance indicators are: If the principal receives a score in the final School Development Plan evaluation of equal / greater than 65 then the school principal is declared successful or feasible, but if the score is less than 65 then the principal is declared unsuccessful or not feasible. Based on the results of the analysis in each cycle shows an increase in the Principal's Performance in compiling School Development Plans namely: an increase in the number of Principals who are able to compile School Development Plans from cycle I to cycle II. Thus it can be concluded that through the Workshop activities can improve the Principal's Performance in preparing School Development Plans on Rayon 2 in Pandeglang. mere school head administration. This is evidenced by obtaining a value of 72.14 in the first cycle and increased to 85.71 in the second cycle.
\end{abstract}

Keywords: School Development Plan, Wokshop, Principal

\section{PENDAHULUAN}

Kepala Sekolah memiliki peran

yang sangat kuat dalam

mengkoordinasikan semua sumber

daya pendidikan yang tersedia.
Kepemimpinan Kepala Sekolah merupakan salah satu faktor yang dapat mendorong sekolah untuk dapat mewujudkan Visi, Misi, Tujuan dan 
Sasaran Sekolah melalui program program yang dilakukan secara berencana dan bertahap. Oleh karena itu Kepala Sekolah dituntut memiliki kemampuan kemampuan manajemen dan kepemimpinan yang tangguh agar mampu mengambil keputusan dan inisiatif/prakarsa untuk meningkatkan mutu sekolah.

Tugas dan fungsi Kepala sekolah adalah mengelola penyelanggaraan Manajemen Berbasis Sekolah (MBS) di sekolah masing masing, mengingat sekolah merupakan unit terdepan dalam penyelenggaraan MBS, salah satu tugas Kepala Sekolah adalah menyusun Rencana Pengembangan Sekolah (RPS). Hal ini sesuai dengan Manajemen Berbasis Sekolah bahwa, Kepala Sekolah menjalankan salah satu tugas dan fungsinya adalah menyusun Rencana dan Program Pengembangan Sekolah dengan melibatkan semua unsur antara lain : Kepala Sekolah, Wakil Kepala Sekolah, Guru, Tata Usaha, Wakil Siswa (OSIS), Wakil orang tua siswa, Wakil Organisasi Profesi, Wakil Pemerintah dan Tokoh Masyarakat (Depdiknas, tahun 2003 : 29).

Panduan pelaksanaan Workshop Pendayagunaan MBS Kecamatan / Kota dalam penyusunan
Rencana Pengembangan Sekolah (RPS) Non DBEP menjelaskan bahwa; Salah satu upaya meningkatkan Manajemen Berbasis Sekolah yang diminta Kepala Dinas Dikbud Kota. adalah Sekolah mampu Menyusun Rencana Pengembangan Sekolah (RPS) sehingga asas transparansi, akuntabilitas dan bekerja berdasarkan rencana dapat tercapai (Depdikbud Kota ., tahun 2002).

Namun dalam kenyataan di lapangan masih banyak Kepala Sekolah belum menyusun Rencana Pengembangan Sekolah disebabkan oleh beberapa hal antara lain : (1) Kepala Sekolah sebagai pemimpin belum memahami secara tuntas tentang Penyusunan Rencana Pengembangan Sekolah (RPS) sebagai akibat kekurangan informasi yang didapat. (2) Tugas Kepala Sekolah utamanya di Rayon 2 sangat komplek mengingat di Sekolah masih terbatasnya tenaga Staf Tata Usaha, (3) Sementara ini Kepala Sekolah menyelenggarakan pendidikan di sekolah tidak berdasarkan perencanaan yang jelas (tidak memiliki RPS khususnya sekolah non DBEP).

Berdasarkan informasi dan pengamatan di lapangan secara langsung bahwa Kepala Sekolah yang ada di Rayon 2 belum memahami dan 
mampu menyusun Rencana

dalam

menyusun

Rencana

Pengembangan Sekolah (RPS) maka Pengembangan Sekolah (RPS), oleh perlu dilakukan upaya peningkatan kemampuan Kepala Sekolah dalam menyusun Rencana Pengembangan Sekolah melalui workshop.

Kepemimpinan Kepala Sekolah merupakan salah satu faktor yang dapat mendorong sekolah untuk dapat mewujudkan Visi, Misi, tujuan dan sasaran sekolah melalui program program yang dilakukan secara berencana dan bertahap. Oleh karena itu Kepala Sekolah dituntut memiliki kemampuan manajemen dan kepemimpinan yang tangguh agar mampu menghasilkan keputusan dan prakarsa untuk meningkatkan mutu sekolah.

Rencana Pengembangan Sekolah (RPS) sangat perlu dimiliki oleh sekolah untuk memberi arah dan bimbingan para pelaku sekolah dalam rangka untuk mecapai tujuan sekolah dengan resiko yang kecil dan mengurangi ketidakpastian masa depan.

Berdasarkan informasi dan pengamatan langsung di lapangan, sebagian besar Kepala sekolah yang ada di Rayon 2 belum memahami dan belum mampu menyusun RPS, hal ini disebabkan kurangnya informasi serta bimbingan yang mereka dapatkan karena itu perlu dilakukan upaya peningkatan kemampuan Kepala Sekolah dalam menyusun RPS melalui Workshop.

Berdasarkan latar belakang masalah seperti diuraikan di atas maka masalah yang akan diteliti adalah " Bagaimana meningkatkan kemampuan Kepala Sekolah dalam menyusun RPS melalui workshop di Rayon 2 Pandeglang?

Tujuan Penelitian ini adalah untuk mengetahui apakah dengan kegiatan workshop dapat meningkatkan kemampuan kepala sekolah dalam menyusun Rencana Pengembangan Sekolah (RPS).

\section{KAJIAN TEORITIK}

Dengan dasar pemikiran seperti itu kemampuan pemimpin Kepala Sekolah sebenarnya dapat ditanamkan, dilatih, dibina agar memiliki kemampuan menyusun perencanaan sekolah yang telah diisyaratkan. Hal ini sesuai dengan tuntutan PP.No 19 tahun 2005, khususnya yang terkait dengan pasalpasal yang mengatur kompetensi Kepala Sekolah yaitu : PP No.19 tahun 2005, khususnya yang terkait dengan pasal pasalnya yang mengatur 
kompetensi Kepala Sekolah yaitu pasal 28 memiliki kualifikasi sebagai pendidik, Pasal 38, Memiliki kemampuan kepemimpinan dan kewirausahaan, Pasal 39, Memiliki kualifikasi sebagai pengawas, Pasal 49 memiliki kemampuan mengelola dan melaksanakan satuan pendidikan, Pasal 52 Memiliki kemampuan menyusun pedoman manajemen sekolah dan pasal 53 Memiliki kemampuan menyusun perencanaan (Depdiknas, tahun 2005).

Pengetahuan, keterampilan, dan kecakapan manusia dikembangkan melalui belajar. Banyak cara yang dapat dilakukan untuk memperoleh ketiga aspek tersebut seperti belajar di dalam sekolah, luar sekolah, tempat bekerja, sewaktu bekerja, melalui pengalaman, dan melalui workshop. Worshop adalah suatu pertemuan ilmiah dalam bidang sejenis (pendidikan) untuk menghasilkan karya nyata. (Badudu,1988:403). lebih lanjut (Harbinson,1973:52) mengemukakan bahwa pendidikan dan pelatihan secara umum diartikan sebagai proses pengalihan keterampilan dan pengetahuan yang terjadi di luar sistem persekolahan yang sifatnya lebih heterogen dan kurang terbakukan dan tidak berkaitan satu sama lainya karna memiliki tujuan yang berbeda.

Nadler

(1970:40-41)

membedakan pendidikan dan pelatihan. Latihan merupakan kegiatan yang dirancang untuk memperbaiki unjuk kerja (perfomance) dalam tugas yang dihadapi ataupun di kerjakan. Tujuannya mengintroduksikan tingkahlaku yang ada sekarang sehingga menghasilkan tingkah laku tertentu. Sedangkan pendidikan didefinisikan sebagai kegiatan pengembangan sumberdaya manusia untuk memperbaiki keseluruhan kemampuan dalam tugas yang sekarang ditangani. Selanjutkan, Nadler (1983:7) mengetengahkan tiga jenis program belajar yaitu: (1) latihan, yaitu belajar yang berkenaan dengan pekerjaan individu sekarang, (2) pendidikan, yaitu belajar yang berkenaan dengan masadepan, tetapi pekerjaan bagi individu peserta didik tersebut dikenali dan dipersiapkan, dan (3) pengembangan, yaitu belajar bagi pertumbuhan individu atau organisasi secara umum.

Dalam banyak bidang pelatihan (workshop) hal tersebut memang sangat sulit untuk tidak mengatakannya mustahil (dilakukan validasi dan evaluasi). Bidang yang dimaksud misalnya manajemen atau 
pelatihan hubungan manusia umum sifatnya. Dalam hal ini semua bentuk pelatihan (workshop) tidak dapat memperlihatkan hasil yang objektif. Pelatihan umumnya mempunyai masalah mengenai prestasi penatar dalam mengajar, yaitu masalah evaluasi dan validasi kelangsungannya. Jika pelajaran telah diajarkan dengan baik dan penatar telah belajar pelajaran tersebut sesuai dengan ukuran penatarnya maka efektivitas pelatihan sudah dianggap valid. Pelatihan merupakan proses perbantuan (facilitating) guru untuk mendapatkan keefektivan dalam tugas-tugas mereka sekarang dan masa yang akan datang melalui pengembangan kebiasaan berfikir, bertindak, keterampilan, pengetahuan dan sikap yang sesuai (Dahana and Bhatnagar,1980: 672). Pelatihan pada dasarnya berkenaan dengan persiapan pesertanya menuju arah tindakan tertentu yang dilukiskan oleh teknologi dan organisasi tempat ia bekerja serta sekaligus memperbaiki unjuk kerja, sedangkan pendidikan berkenaan dengan membukakan dunia bagi peserta didik untuk memilih minat, gaya hidup dan kariernya.

Procton (1983: 12) memberikan batasan bahwa latihan bisa disebut latihan kerja bilamana kegiatan tersebut dilakukan dengan sadar untuk menyajikan materi agar berlangsung proses belajar. Dengan latihan kerja ini dicoba mengarahkan kembali pengalaman-pengalaman belajar tadi kedalam jalur-jalur yang positif dan bermanfaat serta mendorong mereka untuk melakukan kegiatan.

Procton dan Thornton (1983:9) mengemukakan bahwa kalangan manajemen terlalu membebankan harapan besar terhadap pelatihan, sementara pelaihan itu sendiri diselenggarakan kurang mengarah kepada kebutuhan sebenarnya. Demikian juga Feldman dan Arnold (1983:83) mengemukakan bahwa sering kali program pelatihan diselenggarakan begitu banyak persoalan sehingga malah tidak mampu memberikan informasi memadai dan penting sesuai dengan kebutuhan dan harapan peserta pelatihannya. Yang diperlukan oleh banyak organisasi adalah bukan sejumlah teori tetapi hal-hal yang bersifat praktis dan mudah diimplementasikan di lapangan. Untuk itu, organisasi perlu memikirkan bagaimana mengidentifikasikan kecakapan-kecakapan yang relevan dengan tugas dan menyelenggarakan pelatihan untuk mengembangkan kecakapan-kecakapan tersebut. 
Kiranya sudah cukup banyak bukti bahwa pelatihan (inservice training) mampu meningkatkan kemampuan peserta didik. Penyegaran keterampilan-keterampilan standar pengajaran termasuk didalamnya menyusun alat evaluasi belajar akan meningkatkan mutu pengajaran dan pada giliranya meningkatkan prestasi peserta didik. Hal ini dilaporkan oleh Haetleu dan Swanson (1984) yang melakukan penelitian di mesir. Pancangan Penelitian yang digunakan adalah Penelitian regresi majemuk. Sembiring dan Livingstone (1981) melaporkan hasil penelitianya terhadap 124 Sekolah Menengah di Indonesia dengan rancangan regresi majemuk juga menemukan adanya pengaruh tersebut. Nasution dkk (1976) yang meneliti 40 sekolah dengan rancangan experimental di Indonesia, juga menemukan hubungan positif antara pelatihan guru dengan mutu pengajaran dan prestasi peserta didik.

Husen (1987) yang mengadakan penelitian di Biswana, juga menemukan pengaruh meyakinkan dari banyaknya pelatihan guru dengan mutu pengajaran dan prestasi peserta didik. Demikian juga Armitage dkk (1986) melaporkan lahil penelitian mereka di Brasil menemukan pengaruh positif meyakinkan dari penelitian yang diikuti guru dengan mutu pengajaran dan prestasi peserta didik. Pelatihan atau pendidikan dan latihan sekalipun sering dilakukan, masih diremehkan sebagai faktor motifasi yang ampuh. Peter Drucker (dalam Bambang Kusrianto, 1993:118) menunjukan bahwa justru dengan pelatihan yang terus meneruslah orang Jepang merasa makin besar tanggung jawabnya terhadap pekerjaan dan alatalat yang digunalkannya. Pelatihan membuat orang makin mengerti akan prestasinya, prestasi peserta didiknya, serta prestasi sekolah dan berusaha untuk meningkatkan prestasi-prestasi itu.

Berdasarkan uraian diatas dapat dipahami mengenai makna kata pendidikan dan pelatihan (workshop) pada dasarnya adalah suatu proses untuk meningkatkan pengetahuan, sikap, keterampilan dan kemampuan seorang Kepala sekolah atau sekelompok kepala sekolah dalam menyusun Rencana Pengembangan Sekolah yang ditunjukan oleh karya nyata yang berupa dokumen RPS.

\section{METODE PENELITIAN}

Metode Penelitian yang digunakan adalah Penelitian Tindakan Sekolah (PTS). Penelitian Tindakan 
Sekolah ini dilaksanakan di Rayon 2 Kecamatan Kaduhejo Alasan utama dari hasil pengamatan langsung dan informasi yang di terima, bahwa sebagian besar Kepala Sekolah yang ada di Rayon 2 belum memiliki Rencana Pengembangan Sekolah (RPS) karena kepala sekolah belum mampu menyusun RPS yang sesuai dengan keadaan dan kondisi sekolah masing-masing.

Selanjutnya, tahap observasi dilakukan oleh peneliti pada saat Kepala Sekolah menyusun RPS di setiap pertemuan, baik secara individu maupun kelomppok. Pengamatan dilakukan terhadap setiap Kepala Sekolah tentang kerjasama, aktivitas, Memperhatikan hasil pada siklus I peneliti melakukan refleksi terhadap hasil yang diperoleh. Hambatan-hambatan yang ditemukan pada sikus I seperti efektivitas penyampaian informasi-informasi tentang cara penyusunan RPS yang masih bersifat umum terbukti kepala sekolah belum mencapai nilai maksimal pada aspek 1 yaitu kelengkapan elemen RPS, aspek 2 yaitu, tentang kejelasan tujuan RPS, aspek 3 tentang ketepatan / kesesuaian program dengan tujuan RPS, aspek 4 yaitu kemanfaatan program, aspek 5 yaitu strategi presentasi dalam menyusun RPS dengan menggunakan format observasi.

Adapun skala yang digunakan adalah sekala Likert dengan lima katagori sikap yaitu: sangat tinggi, tinggi, sedang, rendah dan sangat rendah. Penilaian dilakukan dengan memberikan skor pada kolom yang tersedia dengan ketentuan sebagai berikut: skor 5 = sangat tinggi, skor $4=$ tinggi, skor $3=$ sedang, skor $2=$ rendah, dan skor 1 = sangat rendah . Sehingga skor maksimal adalad $4 \times 5$ $=20$.

\section{HASIL PENELITIAN DAN}

\section{PEMBAHASAN}

implementasi / pelaksanaan dan aspek 8 tentang optimalisasi sumber daya sekolah. belum mencapai nilai maksimal dan belum optimalnya bimbingan /informasi yang diberikan secara individual maupun kelompok dalam penyusunan RPS. Hambatan tersebut disempurnakan dalam siklus II.

Pada siklus II kegiatan yang dilakukan adalah mendiskusikan hambatan-hambatan yang dihadapi dalam penyusunan RPS di siklus pertama. Peneliti menjelaskan lebih rinci tentang cara penyusunan RPS utamanya pada aspek 1 yaitu 
bagaimana cara merumuskan visi, misi, dan tujuan sekolah (kelengkapa elemen RPS). Aspek 2 yaitu bagaimana merumuskan tujuan RPS agar menjadi jelas. Aspek 3 yaitu bagaimana menyesuaikan program dengan tujuan RPS. Aspek 4 bagaimana menyusun program agar betul betul bermanfaat. Aspek 5 yaitu bagaimana menyusun strategi implementasi pelaksanan, siklus 2 bagaimana mengoptimalisasi sumber daya sekolah. strategi implementasi / pelaksanaan serta memberikan bimbingan lebih intensif terhadap kepala sekolah yang memperoleh nilai kurang pada siklus I.

Berdasarkan hasil penelitian dapat diketahui bahwa melalui workshop Kepala Sekolah mampu menyusun RPS yang sesuai dengan kreteria yang ditentukan. Yang pada awalnya sekolah tidak memiliki RPS dan tidak memiliki perencanaan, jadi setelah dibimbing melalui worshop menghsilkan

Rencana

Pengembangan Sekolah (RPS) yang sesuai dengan karakteristik sekolah masing masing, walaupun belum mencapai optimal namun sudah ada peningkatan. Pada siklus I diperoleh nilai rata terhadap RPS yang disusun yaitu 72,14 dan pada siklus II terjadi peningkatan sebesar 13,57 , sehingga nilai rata rata RPS yang dihasilkan pada siklus II adal 85,71.

\section{SIMPULAN}

Pertama, dengan diterapkannya Manajemen Berbasis Sekolah yang merupakan salah satu bentuk pengelolaan sekolah yang menempatkan sekolah sebagai pemegang peran utama pengelolaan sekolah dalam upaya peningkatan mutu. Maka setiap sekolah perlu menyusun RPS secara baik. dengan dilaksanakan workshop penyusunan RPS yang dilakukan secara kekeluargaan, kepala sekolah merasa terbantu dalam melaksanakan tugas tugasnya selaku kepala sekolah khususnya dalam penyusunan perencanaan sekolah. Disamping hal tersebut sekolah mimiliki RPS yang bertujuan untuk : (1) agar tujuan yang telah ditetapkan dapat dicapai, (2) mendukung koordinasi antar pelaku sekolah, (3) adanya keterkaitan dan konsistensi antara perencanaan penganggaran, pelaksanaan dan pengawasn, (4) mengoptimalkan partisipasi masyarakat, (5) penggunaan sumberdaya secara efisien, efektif dan berkelanjutan.

Kedua, dengan workshop kemampuan Kepala Sekolah dapat ditingkatkan utamanya kemampuan 
menyusun RPS yang sebelumnya mereka beranggapan bahwa RPS adalah pelengkap administrasi kepala sekolah belaka. Hal ini dibuktikan dari belum maksimal dalam penyusunan RPS, kemudian pada siklus I kepala sekolah memperoleh nilai 72.14 dan meningkat menjadi 85,71 pada siklus II.

\section{DAFTAR PUSTAKA}
Badan Standar Nasional Pendidikan dan Direktorat Tenaga Kependidikan, Naskah Akademik Standar Kependidikan dan Kompetensi Kepala Sekolah. 2006.

Badudu.J.S. Kamus Besar Bahasa Indonesia, Jakarta: Gramedia. 1988.

Depdiknas. Manajemen Berbasis Sekolah Direktorat Jendral Pendidikan Dasar dan Menengah: Direktorat Tenaga Kependidikan. 2003.

Depdiknas. Panduan Penyusunan dan Implementasi Rencana Pengembangan Pendidikan Kabupaten/ Kota. 2003.

Depdiknas, PP. No. 19 Tahun 2005.

Depdiknas. Direktorat Pembinaan SMP Direktorat Jendral ManajemenDikdasmen. 2006.
Dinas Pendidikan dan Kebudayaan. Panduan Pelaksanaan workshop Pendayagunaan Mbs Kecamatan/ Kota dalam Penyusunan RPS Non DBEP Kota. 2007.

Kepmendiknas, No 162 Tahun.

Pedoman Penugasan Guru Sebagai Kepala Sekolah. 2003.

Procton and Thornton. Latihan Kerja Buku Pegangan Bagi Para Manage. Jakarta: Bina Aksara. 1983.

PT Buku Kita. Standar Kompetensi Kepala Sekolah, Jakarta: Pustaka Yustisia. 2007. 